\title{
Towards Methane Combustion Mechanism on Metal Oxides Supported Catalysts: Ceria Supported Palladium Catalysts
}

\author{
M. Chrzan ${ }^{1} \cdot$ D. Chlebda ${ }^{1} \cdot$ P. Jodłowski ${ }^{2}$ E. Salomon ${ }^{1} \cdot$ A. Kołodziej $^{3} \cdot$ A. Gancarczyk ${ }^{3} \cdot$ M. Sitarz ${ }^{4} \cdot$ J. Łojewska $^{1}$ (D)
}

Published online: 14 February 2019

(c) The Author(s) 2019

\begin{abstract}
The application of methane as a fuel in the automotive industry shows an increasing tendency, but its release into the atmosphere is detrimental due to its very high greenhouse effect. For this reason, new solutions for cleaning systems of exhaust gas from methane engines are in demand. This study focuses on thorough characterisation of active centres, structure-activity relationships, and reaction steps on palladium ceria supported catalysts of different loading, using the in situ FTIR method with different surface probe molecules. The results show substantial activity of low loading $\mathrm{Pd} / \mathrm{CeO} \mathrm{O}_{2}$ catalyst, correlated with its high dispersion. Three types of active centres were found on the catalyst surface: acidic and redox on both the ceria and palladium oxide surfaces, and basic ones on the palladium oxide. The reaction on the $\mathrm{Pd} / \mathrm{CeO}_{2}$ catalyst was shown to proceed via the formation of monodentates, which were a stable reaction intermediate in the temperature range between 150 and $250{ }^{\circ} \mathrm{C}$. The assignment of the intermediates was supported by the in situ FTIR sorption experiments with $\mathrm{CO}, \mathrm{CH}_{4}$ used as probe molecules.
\end{abstract}

\section{Introduction}

Due to growing tendency towards the use of methane powered engines in vehicles, especially those that serve for public transport in big cities, new environmental issues arise in connection with unburnt methane released into the atmosphere. This contributes to the huge and still underestimated overall methane emissions both from stationary sources and dispersed ones. The gravity of the problem lies in the fact that methane is an extremely active greenhouse gas, the effect of which is assessed to be substantially higher than that of carbon dioxide.

The most efficient method of methane abatement from exhaust gases is catalytic combustion. A considerable amount of research on methane oxidation catalysts has been

J. Łojewska

lojewska@chemia.uj.edu.pl

1 Faculty of Chemistry, Jagiellonian University, Kraków, Poland

2 Faculty of Chemical Engineering and Technology, Cracow University of Technology, Kraków, Poland

3 Institute of Chemical Engineering, Polish Academy of Sciences, Gliwice, Poland

4 Faculty of Material Science and Ceramics, AGH Technical University, Kraków, Poland conducted over the past 20 years. Refs. [1-10] are selected examples of this research. Most of the studies have focused on $\gamma$-alumina-supported $\mathrm{Pd}$, which is still recognised as the most effective [11-16]. However, the major problem associated with palladium catalysts is their deactivation connected with their relatively high volatility and sensitivity to poisoning by sulphur [12]. Other metal oxides have also been found to exhibit less (though still considerable) activity towards methane oxidation $[4,12,17-25]$. It has been shown that the addition of a small amount of Pd improves the catalytic performance of these oxides [26-29]. Some of them, for example ceria [30-33] and zirconia [34], can be regarded as both active metal oxides and supports for palladium catalysts.

Among several rare earths, ceria is the most common support, because of its numerous advantages. Firstly, this oxide enhances the dispersion of the noble metal while also promoting both noble metal-supported catalyst oxidation and reduction under reaction conditions. Ceria, as an additive to a catalyst, increases the thermal stability of other supports and has the ability to store and release oxygen, hydrogen and sulphur [31, 35-37] and also to suppress partial oxidation products carbon monoxide [30,33]. The properties of ceria support come from two oxidation states of cerium and ability to form surface and bulk vacancies. It interacts synergistically with palladium, favouring methane oxidation at low temperatures and improving the performance of materials 
containing Pd at low and high temperatures [4, 33, 38, 39]. However, ceria can also be considered as a redox catalyst in its own right, due to the ability to shift between different oxidation states as mentioned above. Thus, Pd can be considered as a promotor of ceria when in small amounts.

For all the reasons given above, ceria has become a metal oxide of interest over the many areas in which the industry has been dealing with energy, environment protection and transport. The literature reports that, under reductive conditions, the surface sites are susceptible to reduction, favoured by the high mobility of oxygen into the $\mathrm{CeO}_{2}$ lattice with the creation of oxygen vacancies [40-42] or by outgassing at high temperature. High-temperature treatment in an oxidising atmosphere results in the formation of $\mathrm{M}-\mathrm{O}$ surface complexes with ceria [31]. These complexes show an improved degree of metal dispersion. However, cyclic redox aging conditions result in complete degradation of surface complexes by sintering or agglomeration [30]. Ceria promotes the oxidation of active phase metal to oxide.

Designing an efficient catalyst for a given process should be based on thorough investigation of structure-activity relationships followed by determination of the reaction mechanism, rather than relying on combinatory chemistry. In fact, the mechanism of methane catalytic combustion even on the most widespread palladium supported catalyst seems still far from being fully understood. There are several problems which can be addressed in this respect. One of them originates from the huge energetic barrier of the $\mathrm{C}-\mathrm{H}$ bond breakage, which proceeds according to a radical mechanism. For this reason, and due to analytical limitations, the precise steps involved in this process have not yet been recognised. Although several groups, such as [43-46] studied the stable intermediate products that come after the rate determining step using in situ FTIR methods, ambiguous band assignment still prevents the formulation of trustworthy parallel-consecutive oxidation pathways for methane surface evolution. Finally, it has not been elucidated whether methane oxidation proceeds via the adsorption step by forming methoxy groups in accordance with the Langmuir-Hinshelwood mechanism, or without adsorption by the Rideal-Eley mechanism.

The mechanism of methane oxidation on ceria proposed in the literature involves activation of $\mathrm{CH}_{4}$ on its surfacepossibly on a surface coordinatively unsaturated site or on surface lattice oxygen of $\mathrm{CeO}_{2}$ facilitated by the active lattice oxygen species present. On the $\mathrm{CeO}_{2}$ surface. The role of acid-base sites, splitting the $\mathrm{C}-\mathrm{H}$ bond with formation of stabilised surface $\mathrm{OH}$ species [31], cannot be excluded. Moreover, it has been found that $\mathrm{CeO}_{2}$ stabilises $\mathrm{PdO}$ [47], since it hinders $\mathrm{PdO}$ reduction and promotes $\mathrm{Pd}^{0}$ reoxidation. Kennely and Farrauto $[48,49]$ proposed that $\mathrm{CeO}_{2}$ stabilises active $\mathrm{PdO}$. Such stabilisation was claimed to avoid catalyst deactivation by increasing the temperature of
PdO decomposition, but also to favour catalyst regeneration by increasing the temperature of $\mathrm{Pd}^{0}$ reoxidation. This is a consequence of the labile oxygen that can rapidly change valence states and in this way pump oxygen into metals.

This study approaches the evaluation of active centres and methane oxidation mechanism for a series of palladiumceria catalysts of different loadings by using the in situ FTIR method and different probe molecules. The probe molecules were selected in such a way as to provide insight into the structure of active centres present on pure oxide and $\mathrm{Pd} /$ $\mathrm{CeO}_{2}$ of different $\mathrm{Pd}$ concentration and, into the intermediates in methane combustion mechanisms.

\section{Experimental}

\subsection{Sample Preparation}

Samples were prepared using an impregnation method where pre-calcined cerium (IV) oxide (Alfa Aesar, 99.5\% min) was used as a support. In order to deposit the catalyst the pre-calcined ceria support was immersed in methanol solution ( $\mathrm{POCH}$, analytical grade) of palladium acetate (Sigma Aldrich, reagent grade $98 \%$, S. A. $30-50 \mathrm{~m}^{2} / \mathrm{g}$ ) for $1 \mathrm{~h}$ at room temperature. The samples were prepared in two concentrations: $0.7 \mathrm{wt} \%$ and $1.6 \mathrm{wt} \%$ of $\mathrm{PdO}$ in $\mathrm{CeO}_{2}$ from palladium acetate solution of $0.001 \mathrm{M}$ and $0.01 \mathrm{M}$, respectively. Catalysts were dried at room temperature for $12 \mathrm{~h}$. The temperature has then been raised to $550{ }^{\circ} \mathrm{C}$ with a ramp of $3{ }^{\circ} \mathrm{C} / \mathrm{min}$ and maintained constant during $6 \mathrm{~h}$ in a static air condition. The obtained solids have been grinded and fraction with $400-500 \mu \mathrm{m}$ grain size has been selected for the reported experiments.

\subsection{Methods}

\subsubsection{FTIR In Situ}

In situ DIRFT analysis was carried out using a THERMO/ Nicolet 5700 spectrometer equipped with an MCT detector and Praying Mantis High Temperature Reaction Chamber with ZnSe windows (Harrick). Prior to in situ DIRFT analysis, the supported catalysts were fractionated to obtain grains in the range of $400-500 \mu \mathrm{m}$. Spectra were obtained by averaging 64 scans with a resolution of $4 \mathrm{~cm}^{-1}$. The spectrum of the dehydrated catalyst sample in a helium flow was used as a background.

The in situ experiments were performed on the precalcined $\left(500{ }^{\circ} \mathrm{C}\right.$ in air for $\left.6 \mathrm{~h}, 25 \mathrm{~cm}^{3} / \mathrm{min}\right)$ and dehydrated $\left(110^{\circ} \mathrm{C}\right)$ samples. Measurements were coupled with adsorption of selected probe molecules: methanol, carbon 
monoxide, and methane. The following temperature programmed experimental procedures were used:

1. Adsorption of methanol: adsorbed methanol interaction with the dehydrated catalyst at different temperatures. A mixture of $0.2 \mathrm{~mol} \% \mathrm{CH}_{3} \mathrm{OH} / \mathrm{He}$ (Air Products calibration mixture, $\pm 0.5 \%$ rel.) with a total flow rate of $25 \mathrm{~cm}^{3} / \mathrm{min}$ was fed into the reaction chamber at atmospheric pressure at $100{ }^{\circ} \mathrm{C}$ for $1 \mathrm{~h}$, then the mixture was switched off and the sample was flashed with pure $\mathrm{He}$ with a total flow rate $25 \mathrm{~cm}^{3} / \mathrm{min}$. The spectrum was measured and then the temperature was increased by $50{ }^{\circ} \mathrm{C}$ at a heating rate of $2{ }^{\circ} \mathrm{C} / \mathrm{min}$.

2. Adsorption of carbon monoxide: adsorbed $\mathrm{CO}$ interaction with the dehydrated catalyst at different temperatures. A mixture of $0.4 \mathrm{~mol} \% \mathrm{CO} / \mathrm{He}$ (Air Products calibration mixture, $\pm 0.5 \%$ rel.) with a total flow rate of $25 \mathrm{~cm}^{3} /$ min was fed into the reaction chamber at atmospheric pressure at $25^{\circ} \mathrm{C}$ for $1 \mathrm{~h}$, then the mixture was switched off and the sample was flashed with pure He with a total flow rate $25 \mathrm{~cm}^{3} / \mathrm{min}$. The spectrum was measured and then the temperature was increased by $25^{\circ} \mathrm{C}$ at a heating rate of $2{ }^{\circ} \mathrm{C} / \mathrm{min}$.

3. Adsorption of methane: adsorbed methane interaction with the dehydrated catalyst at different temperatures. A mixture of $2 \mathrm{~mol} \% \mathrm{CH}_{4} / \mathrm{He}$ (Air Products calibration mixture, $\pm 0.5 \%$ rel.) with a total flow rate of $25 \mathrm{~cm}^{3} /$ min was fed into the reaction chamber at atmospheric pressure at $50{ }^{\circ} \mathrm{C}$ for $1 \mathrm{~h}$, then the mixture was switched off and the sample was flashed with pure He with a total flow rate $25 \mathrm{~cm}^{3} / \mathrm{min}$. The spectrum was measured and then the temperature was increased by $50{ }^{\circ} \mathrm{C}$ at a heating rate of $2{ }^{\circ} \mathrm{C} / \mathrm{min}$.

4. Dynamic experiments of methane oxidation: methane oxidation on the dehydrated catalyst at different temperatures. Oxidation conditions: $1.600 \mathrm{~mol} \% \mathrm{CH}_{4} /$ $20.900 \% \mathrm{O}_{2} / \mathrm{He}$ (Air Products, calibration mixture, $\pm 0.5 \%$ rel.). A mixture was fed onto the pre-calcined catalyst surface with a total flow of $25 \mathrm{~cm}^{3} / \mathrm{min}$ at a temperature of $50{ }^{\circ} \mathrm{C}$. After achieving stationary conditions in the reaction chamber, the spectrum was measured and then the temperature was increased by $50{ }^{\circ} \mathrm{C}$ at a heating rate of $2{ }^{\circ} \mathrm{C} / \mathrm{min}$.

\subsubsection{Additional Structural Tests}

The crystallinity and phase identification of zirconia coatings were determined using X-ray powder diffraction (XRD) with an X'Pert Pro MPD (PANalytical) diffractometer with $\mathrm{CuK}_{\alpha}$ radiation at $20 \mathrm{~mA}$ and $40 \mathrm{kV}$. The diffraction patterns were collected in the $2 \theta$ range from $10^{\circ}$ to $90^{\circ}$ with a step size of $0.008^{\circ}$ and step time of $0.570 \mathrm{~s}$.
EDX spectra were measured using a JEOL 5400 scanning microscope with a microprobe analyser LINK ISIS (Oxford Instrument).

\subsubsection{Catalytic Activity Tests}

The catalysts obtained by the impregnation method were tested in methane catalytic combustion. The catalytic tests were performed in a Harrick High Temperature Reaction Chamber equipped with an MKS Instruments Cirrus II LM118 (MKS Instruments, Inc., Andover, MA, USA) online quadrupole mass spectrometer. Typically, $25 \mathrm{mg}$ of catalyst with a particle fraction of 400-500 $\mu \mathrm{m}$ was used. During the catalytic tests, the gas composition was set to $2000 \mathrm{ppm}$ $\mathrm{CH}_{4}$ /Air (Air Products, Warsaw, Poland, calibration mixture) and controlled by Brooks 4800 mass flow controllers, resulting in a weight hourly space velocity (WHSV) equal to $150,000 \mathrm{~cm}^{3} \mathrm{~g}^{-1} \mathrm{~h}^{-1}$. Prior to the catalytic tests, the catalyst samples were dehydrated in a $50 \mathrm{~cm}^{3} / \mathrm{min}$ synthetic air flow (Air Products) at $450{ }^{\circ} \mathrm{C}$ for $1 \mathrm{~h}$ with a temperature ramp of $2{ }^{\circ} \mathrm{C} / \mathrm{min}$.

\section{Results}

\subsection{Catalytic Activity of Catalysts}

The catalytic activity is presented as temperature dependence of the conversion of methane, selectivity to $\mathrm{CO}_{2}$ was $100 \%$ for all samples, in Fig. 1. The best catalytic activity in terms of methane conversion was achieved by the palladium catalyst at lower concentration $0.7 \mathrm{Pd} / \mathrm{CeO}_{2}$ at $500{ }^{\circ} \mathrm{C}$. At the same temperature, the $1.6 \mathrm{Pd} / \mathrm{CeO}_{2}$ sample reached only $15 \%$, conversion which is comparable to the bulk oxide

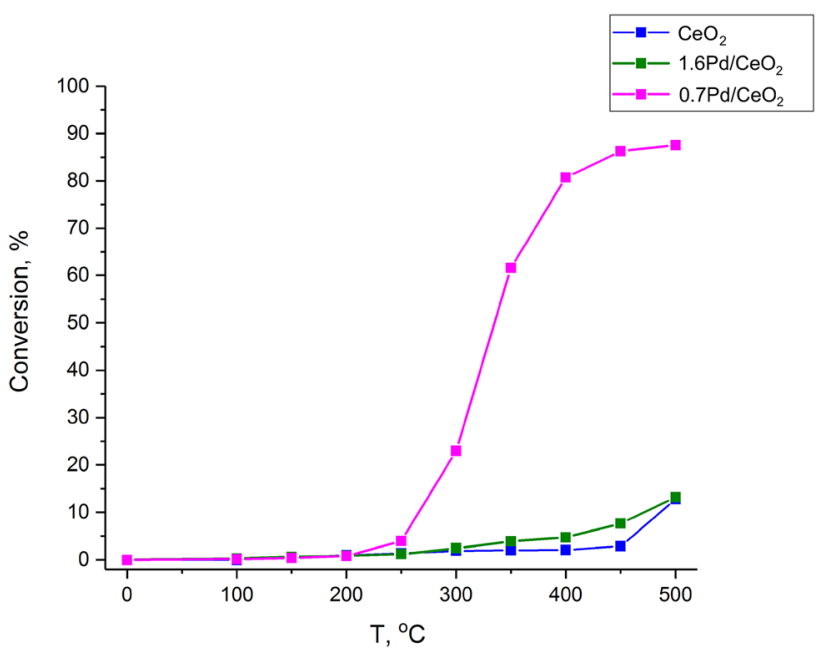

Fig. 1 Conversion profile of methane catalytic combustion for ceria support and palladium catalysts 
support $\mathrm{CeO}_{2}$ sample. For the $1.6 \mathrm{Pd} / \mathrm{CeO}_{2}$ and $\mathrm{CeO}_{2}$ samples, the reaction was ignited at $250{ }^{\circ} \mathrm{C}$.

\subsection{Overall Catalyst Composition}

To determine the elemental distribution of palladium and cerium over the prepared samples, SEM/EDX mapping was performed. The results are summarised in Fig. 2, which shows the spatial distribution of ceria and $\mathrm{Pd}$ on three samples used for this study. The results obtained for $0.7 \mathrm{Pd} / \mathrm{CeO}_{2}$ and $1.6 \mathrm{Pd} / \mathrm{CeO}_{2}$ catalysts (Fig. 2c-h, respectively) indicate that palladium oxide is non-uniformly distributed over the ceria in the form of dispersed crystallites. It must also be emphasised that no additional elements were detected. A comparison of the SEM images in Fig. $2 \mathrm{c}$ and $\mathrm{f}$ indicates much smaller grains and higher dispersion for the $0.7 \mathrm{Pd} /$ $\mathrm{CeO}_{2}$ sample than for $1.6 \mathrm{Pd} / \mathrm{CeO}_{2}$.

The amount of $\mathrm{PdO}$ estimated for the samples equals 1.6 wt $\%$ (2.2 mol\%) for the $1.6 \mathrm{Pd} / \mathrm{CeO}_{2}$ sample and $0.7 \mathrm{wt} \%$ ( $1 \mathrm{~mol} \%$ ) for the $0.7 \mathrm{Pd} / \mathrm{CeO}_{2}$ sample.
The catalysts prepared by the impregnation method were characterised using XRD. The results are presented in Fig. 3a-c. The reflections at $2 \theta=28.5,33.1,47.4,56.3$, $59.2,69.2,76.6,79.3$ and 88.28 belong to the hexagonal ceria phase. The $\mathrm{PdO}$ phase is detected in the sample by the presence of very low intensity peaks at $2 \theta=42.8$ and 69.7. Due to very low intensities of the signals from both samples no quantitative od structural conclusions can be made based on the results.

\subsection{FTIR In Situ Measurements}

Since the vibrational pattern for higher and lower loading catalyst samples are similar, the results obtained for more active $0.7 \mathrm{Pd} / \mathrm{CeO}_{2}$ catalyst are shown. Also, the intensities of $0.7 \mathrm{Pd} / \mathrm{CeO}_{2}$ sample were higher than for the $1.6 \mathrm{Pd} /$ $\mathrm{CeO}_{2}$.

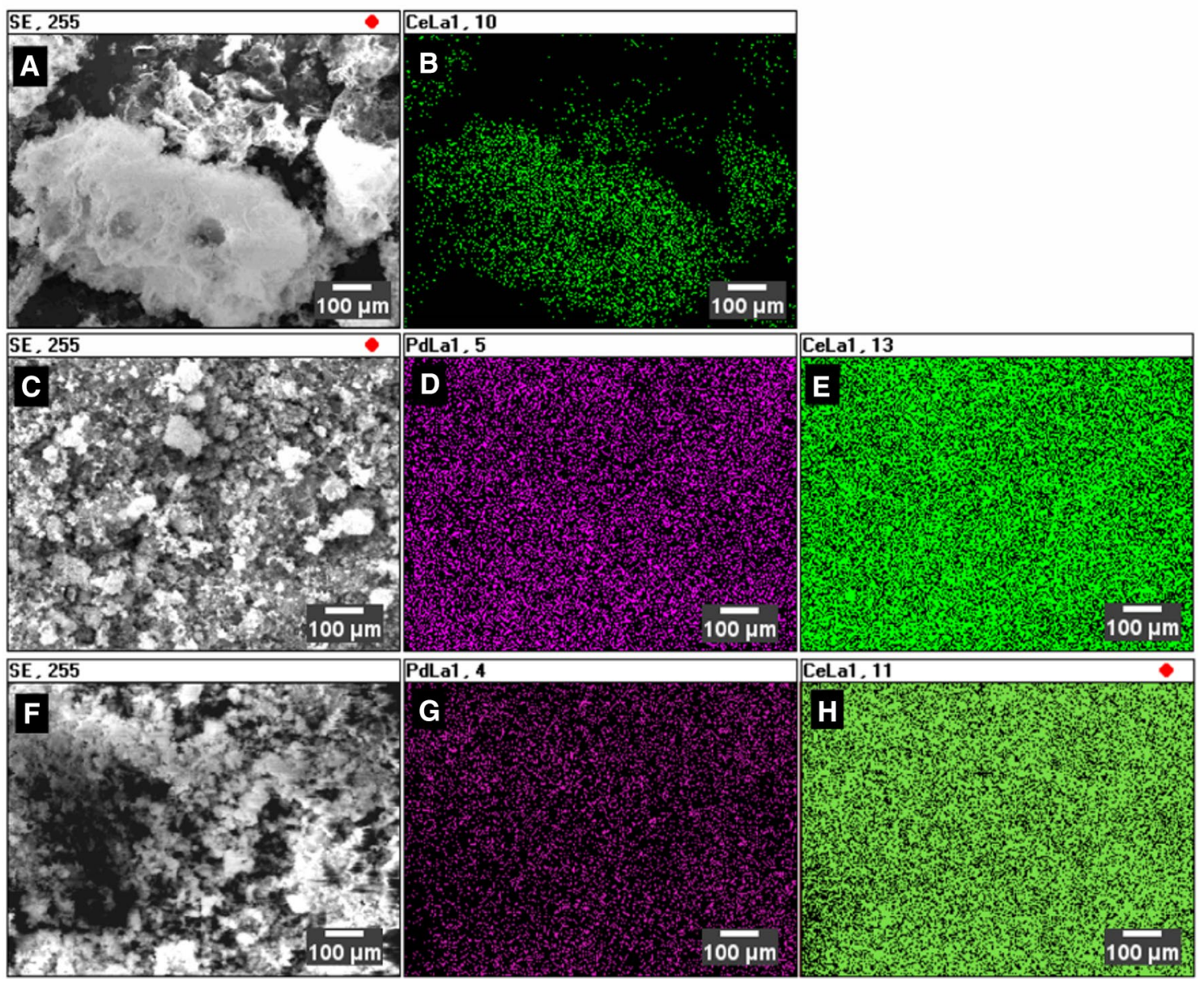

Fig. 2 SEM and EDX maps of ceria and palladium ceria supported catalyst $1.6 \mathrm{PdCeO}_{2}, 0.7 \mathrm{PdCeO}_{2}: \mathbf{a}$, b topography and distribution for ceria, $\mathbf{c}-\mathbf{e}$ for $1.6 \mathrm{Pd} / \mathrm{CeO}_{2}$ and $\mathbf{f}-\mathbf{h}$ for $0.7 \mathrm{Pd} / \mathrm{CeO}_{2}$ 

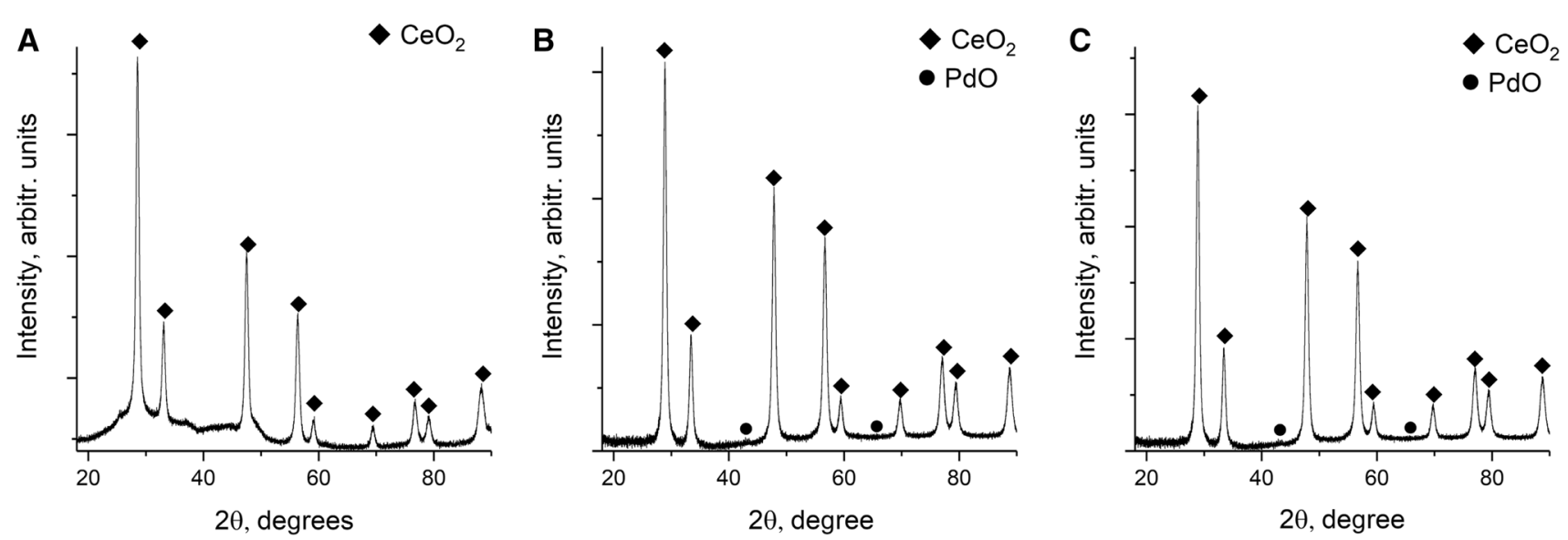

Fig. 3 XRD patterns of the a support $\mathrm{CeO}_{2}$, b $1.6 \mathrm{Pd} / \mathrm{CeO}_{2}$ catalyst and $\mathbf{c} 0.7 \mathrm{Pd} / \mathrm{CeO}_{2}$

\subsubsection{Methanol Adsorption}

Methanol was selected as the probe molecule because of its high reactivity toward oxides (unlike $\mathrm{CO}, \mathrm{H}_{2}$, and $\mathrm{O}_{2}$ ) and its ability to react with various active sites to produce different products.

After methanol adsorption $\left(\mathrm{CH}_{3} \mathrm{OH} / \mathrm{He}, 100^{\circ} \mathrm{C}\right)$ on the reference ceria sample (Fig. $4 \mathrm{a}, \mathrm{b}$ ), the spectrum shows bands at 2942, 2911, 2888 and $2840 \mathrm{~cm}^{-1}(\nu \mathrm{C}-\mathrm{H})$, attributed to the stretching vibrations of the surface methoxy $-\mathrm{OCH}_{3}$ groups [50-53]. At the lower frequency range, their bending equivalents are the bands at 1463, 1371, 1355, 1103 and $1056 \mathrm{~cm}^{-1}$. The bands at 1591 and $1583 \mathrm{~cm}^{-1}$ can be attributed to $-\mathrm{O}-\mathrm{CH}_{2} \mathrm{OH}$ from the partly oxidised methanol groups. Evolution of the adsorbed methanol with increasing temperature results in the appearance of the methanol oxidation products. At $150{ }^{\circ} \mathrm{C}$, the presence of the bands at $1091,1051 \mathrm{~cm}^{-1}(\nu \mathrm{CO})$ and $2721 \mathrm{~cm}^{-1}(\nu \mathrm{C}-\mathrm{H})$ suggests the formation of ether as a product of methanol condensation [54]. An additional product of methanol oxidation is formate, with bands at $1544 \mathrm{~cm}^{-1}(\nu \mathrm{C}=\mathrm{O}), 1386,1359,2931$ and $2848 \mathrm{~cm}^{-1}(\nu \mathrm{C}-\mathrm{H})$ [55-58]. The band at $1436 \mathrm{~cm}^{-1} \mathrm{can}$ be attributed to free carbonates [55, 56, 59].

Methanol adsorption performed on the palladium supported ceria catalyst (Fig. 5a, b) $0.7 \mathrm{Pd} / \mathrm{CeO}_{2}$ showed a similar but richer vibrational pattern. Apart from the bands characteristic of the methanol adsorbed on ceria, new bands evolved at 2938, 2805 and $1371 \mathrm{~cm}^{-1}$. These can be attributed to the vibrations of metoxy groups adsorbed on $\mathrm{PdO}$ active centres. At $150{ }^{\circ} \mathrm{C}$, the evolution of bands at 1103 and $2719 \mathrm{~cm}^{-1}$ indicate ether formation as a result of methanol condensation on ceria active centres [53]. Formate species are also products of methanol oxidation on $\mathrm{PdO}$ active centres, with additional bands at $1580 \mathrm{~cm}^{-1}(\nu \mathrm{C}=\mathrm{O})$, and 1371,1355 and $2805 \mathrm{~cm}^{-1}(\nu \mathrm{C}-\mathrm{H})$ assigned to [55-58]. The bands at around 1560, 1299 and $1031 \mathrm{~cm}^{-1}$ can be
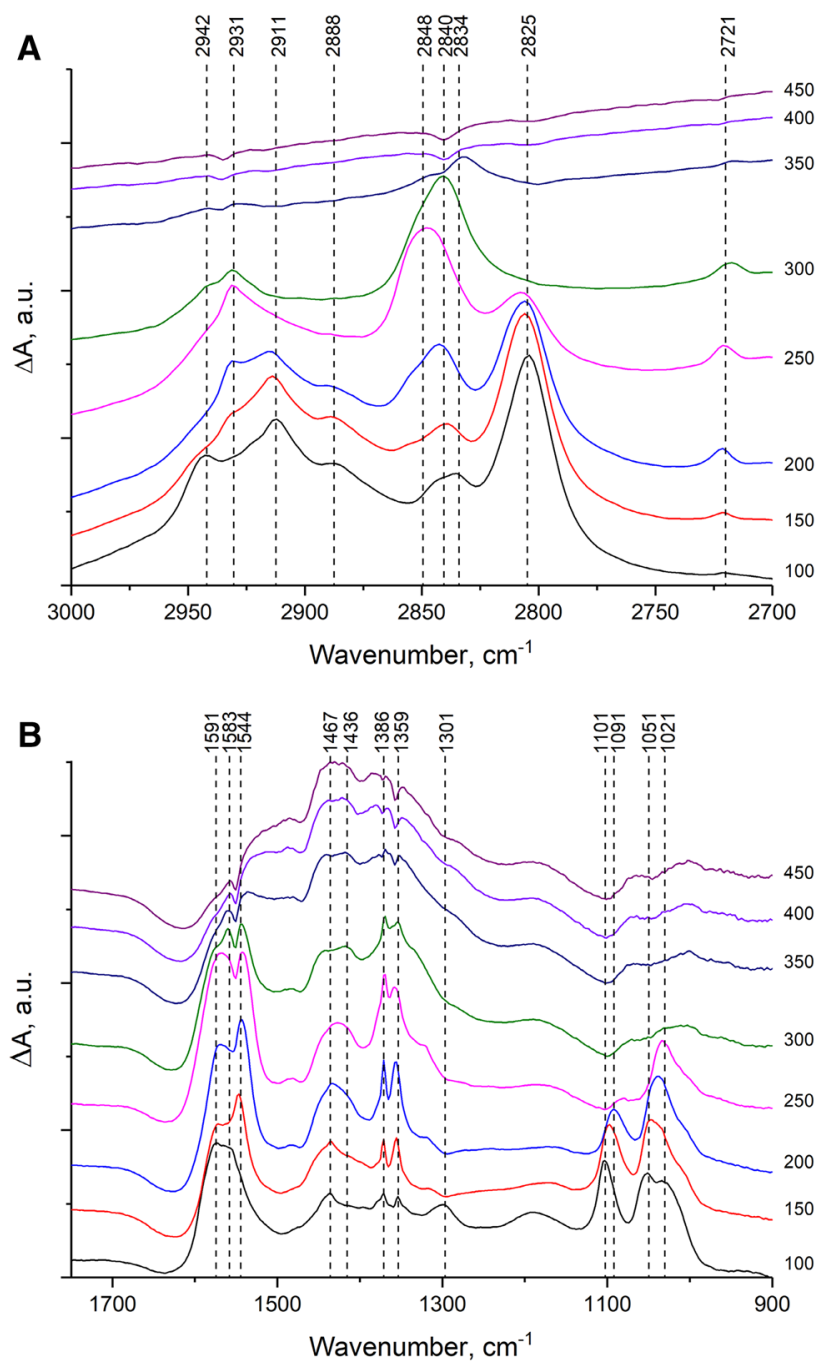

Fig. 4 Difference spectra of methanol adsorbed on ceria support in a $3000-2700 \mathrm{~cm}^{-1}$ and $\mathbf{b} 1750-1000 \mathrm{~cm}^{-1}$ range 

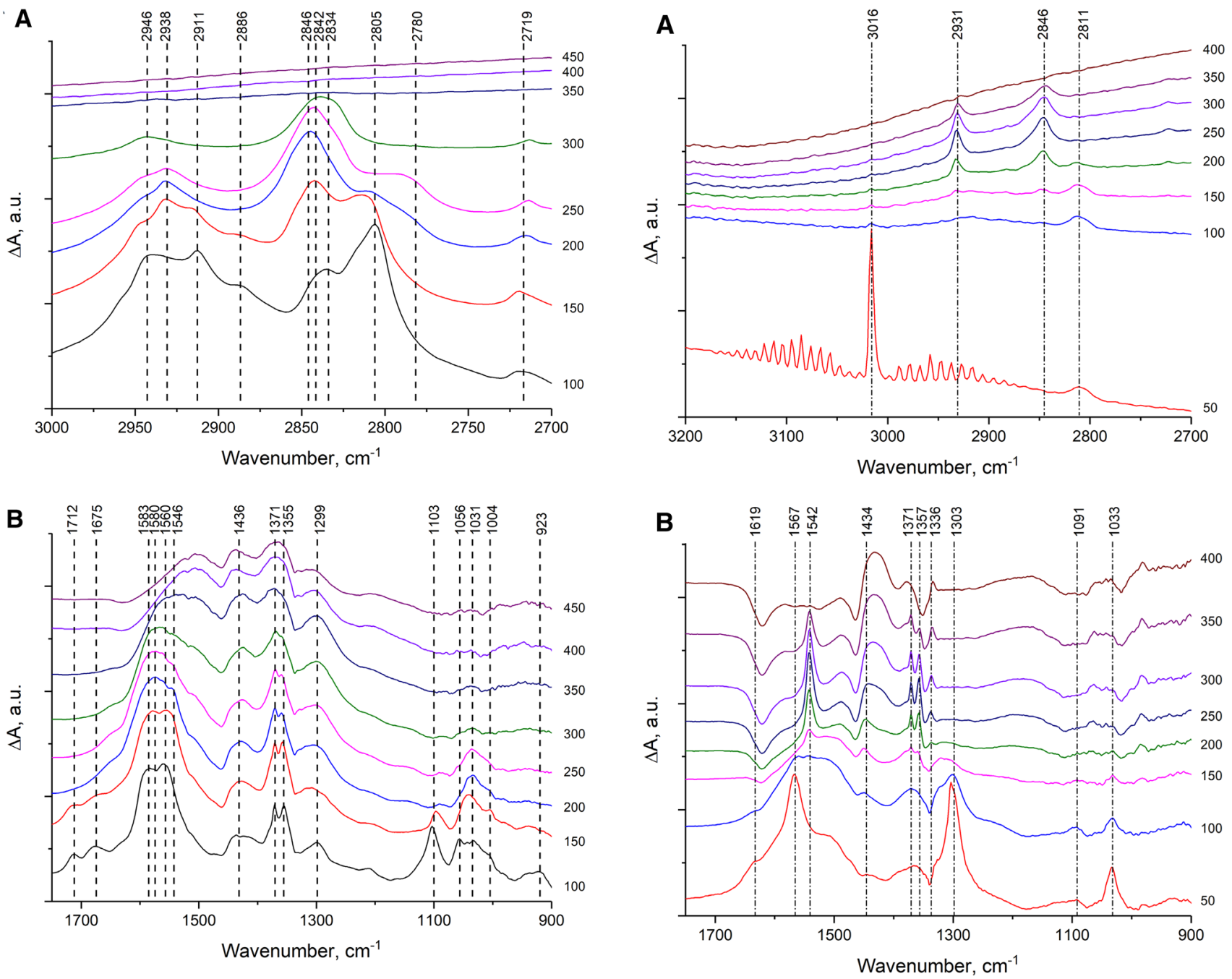

Fig. 5 Difference spectra of methanol adsorbed on $0.7 \mathrm{Pd} / \mathrm{CeO}_{2}$ in a $3000-2700 \mathrm{~cm}^{-1}$ and b $1750-900 \mathrm{~cm}^{-1}$ range

assigned to carbonates, probably to the monodentate form $[55,56,59]$.

\subsubsection{Methane Adsorption}

After methane adsorption $\left(\mathrm{CH}_{4} / \mathrm{He}, 50{ }^{\circ} \mathrm{C}\right)$ on the $0.7 \mathrm{Pd} /$ $\mathrm{CeO}_{2}$ catalyst (Fig. 6a, b), characteristic bands at $3016 \mathrm{~cm}^{-1}$ $\left(\nu_{\text {as }} \mathrm{C}-\mathrm{H}\right)$ and $1303 \mathrm{~cm}^{-1}(\delta \mathrm{C}-\mathrm{H})$ appear due to gaseous methane. After switching methane to helium, additional bands appear, which can be attributed to formate and carbonate species coming from methane evolution on the catalyst surface. Bands at 2931 and $2846 \mathrm{~cm}^{-1}(\nu \mathrm{C}-\mathrm{H})$, and the broad bands at around $1560(\nu \mathrm{C}=\mathrm{O})$ and $1371(\delta$ $\mathrm{C}-\mathrm{H})$ prove the presence of formate groups which form above $250{ }^{\circ} \mathrm{C}$ [55-58]. Let us note that the absorbance of the same bands for higher loaded sample $1.6 \mathrm{Pd} / \mathrm{CeO}_{2}$ (not shown results) is around 6 times lower than that of the 0.7 $\mathrm{Pd} / \mathrm{CeO}_{2}$ sample (Fig. 6a). Carbonate group vibrations can

Fig. 6 Differential spectra of methane adsorbed on $0.7 \mathrm{Pd} / \mathrm{CeO}_{2}$ in a $3000-2700 \mathrm{~cm}^{-1}$ and b $1750-1000 \mathrm{~cm}^{-1}$ range

also be described by bands at 1540 (broad band), 1336 and $1033 \mathrm{~cm}^{-1}(\nu \mathrm{C}-\mathrm{O})$, and are recognised as monodentate carbonates [55-58]. This proves that methane molecules can oxidise on the $0.7 \mathrm{Pd} / \mathrm{CeO}_{2}$ catalyst under oxygen-free conditions. Results suggest that the less oxidative atmosphere promotes the Mars Van Krevelen mechanism of methane oxidation to formate species.

\subsubsection{CO Adsorption}

The spectra recorded after $\mathrm{CO}$ adsorption $\left(\mathrm{CO} / \mathrm{He}, 25^{\circ} \mathrm{C}\right)$ on the palladium-ceria catalyst (Fig. 7a, b) showed the presence of bands which are characteristic of interaction of $\mathrm{CO}$ molecules with cationic centres. The band at $2165 \mathrm{~cm}^{-1} \mathrm{can}$ be attributed to $\mathrm{CO}$ molecules adsorbed on $\mathrm{Ce}^{4+}$ centres [59, 60]. The presence of the band at $2090 \mathrm{~cm}^{-1}$ can be assigned to $\mathrm{CO}$ molecules linearly adsorbed on $\mathrm{Pd}^{+}$centres, and the 

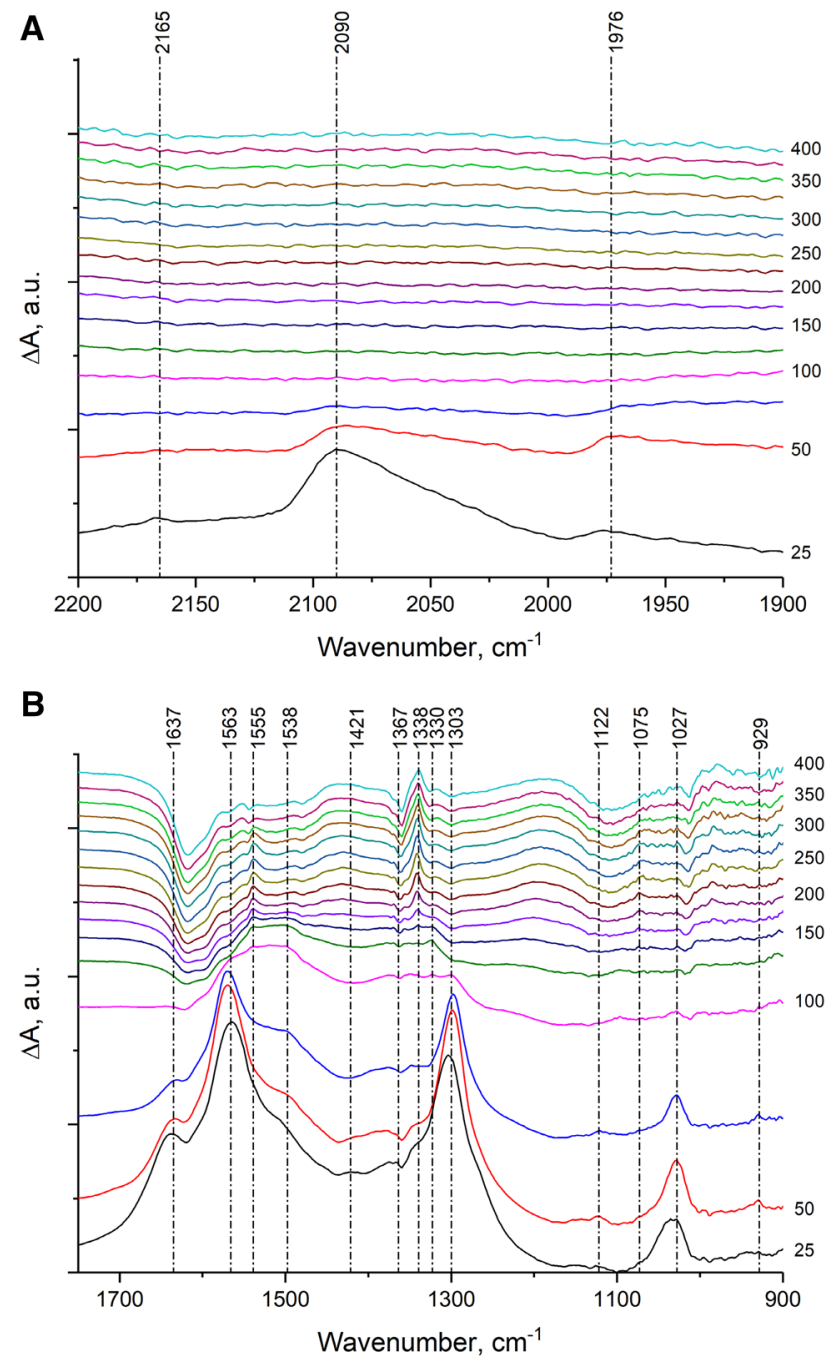

Fig. 7 Differential spectra of $\mathrm{CO}$ adsorbed on $0.7 \mathrm{Pd} / \mathrm{CeO}_{2}$ catalyst in a $2200-1900 \mathrm{~cm}^{-1}$ and b $1750-900 \mathrm{~cm}^{-1}$ range

band at $1976 \mathrm{~cm}^{-1}$ to bridged $\mathrm{CO}$ being adsorbed on $\mathrm{Pd}^{+}$ [60]. Further sample heating under He flow caused the disappearance of these carbonate species due to their decomposition at $100{ }^{\circ} \mathrm{C}$.

At elevated temperature $\left(>200{ }^{\circ} \mathrm{C}\right)$, the only new weak bands that appear at 1550,1330 and $1075 \mathrm{~cm}^{-1}$ can be attributed to monodentate, which is one of the possible products of $\mathrm{CO}$ oxidation on the $\mathrm{PdO}$ active site [55-58].

\subsubsection{Combustion Reaction of Methane}

In situ DRIFT measurements of methane combustion reaction in oxidising conditions on the $0.7 \mathrm{Pd} / \mathrm{CeO}_{2}$ catalyst (Fig. 8a, b) resulted in the evolution of characteristic bands at $3016 \mathrm{~cm}^{-1}\left(\nu_{\text {as }} \mathrm{C}-\mathrm{H}\right)$ and $1304 \mathrm{~cm}^{-1}(\delta \mathrm{C}-\mathrm{H})$ that come from gaseous methane. Results showed additional bands which can be attributed to monodentate carbonates, at 1542,
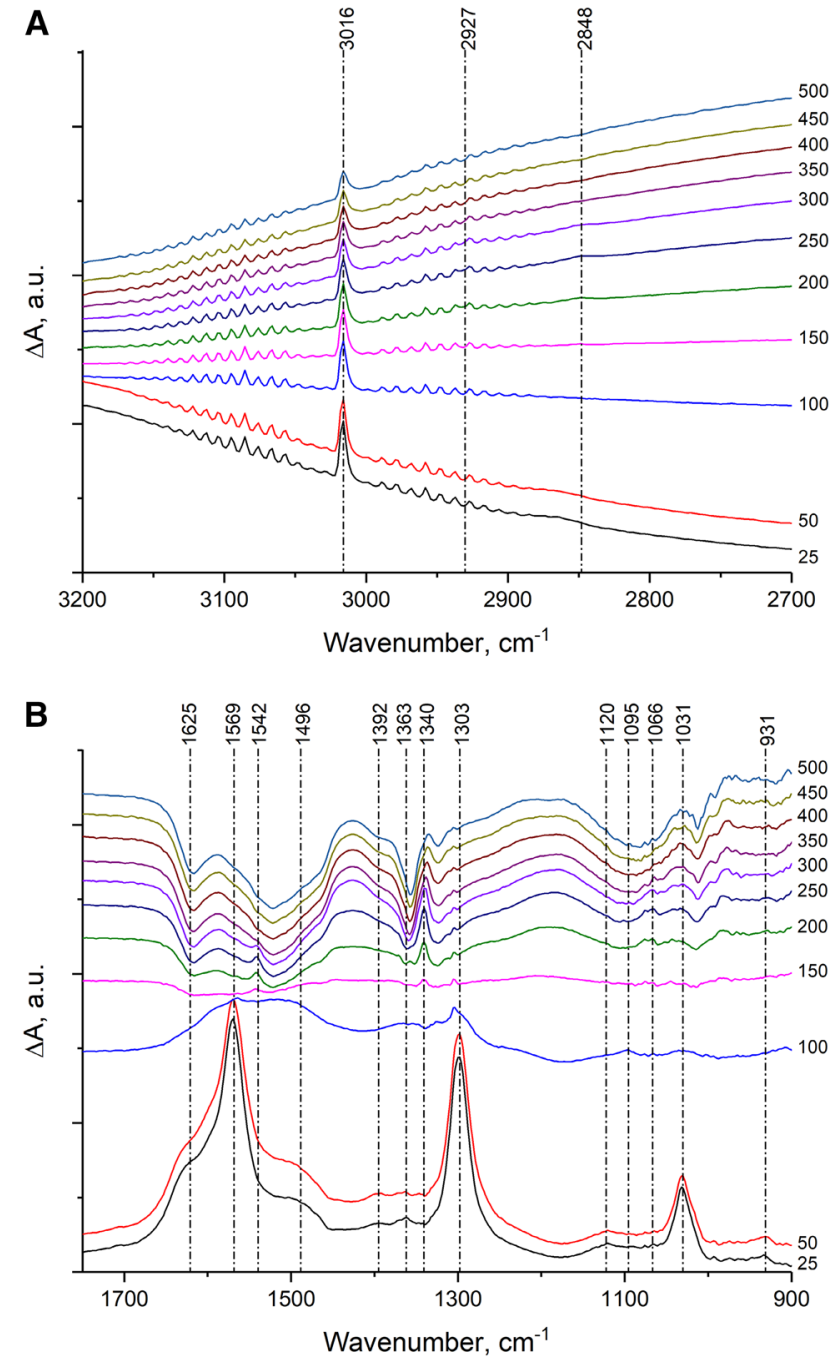

Fig. 8 In situ DRIFT results of the methane combustion on $0.7 \mathrm{Pd} /$ $\mathrm{CeO}_{2}$ in a $3000-2700 \mathrm{~cm}^{-1}$ and b $1750-900 \mathrm{~cm}^{-1}$ range

1340 and $1031 \mathrm{~cm}^{-1}(\mathrm{~V} \mathrm{C}-\mathrm{O})$, and confirm the oxidation of methane [55-58]. Also, very weak bands at 2927 and $2848 \mathrm{~cm}^{-1}$, which are observed at above $150{ }^{\circ} \mathrm{C}$, can be assigned to formates. The confirmation of the species are bands at $1569 \mathrm{~cm}^{-1}(\nu \mathrm{C}-\mathrm{O}), 1392$ and $1363 \mathrm{~cm}^{-1}(\nu \mathrm{C}-\mathrm{H})$. At the final reaction temperature of $500{ }^{\circ} \mathrm{C}$, the presence of the gaseous methane band is detected again.

In the presence of $\mathrm{CO}$ and oxidative conditions, methane is oxidised to monodentate carbonate products.

\section{Discussion}

The phenomenon of high activity of highly dispersed metal oxides including palladium in methane combustion has already been well established in the literature [61]. It has also been pointed out in our previous works $[62,63]$. In this 
study, the phenomenon was observed for a lower loaded 0.7 $\mathrm{Pd} / \mathrm{CeO}_{2}$ (with $0.7 \mathrm{wt} \% \mathrm{PdO}$ ) sample, which showed substantially higher activity than the higher loaded one, $1.6 \mathrm{Pd} /$ $\mathrm{CeO}_{2}$ (1.6 wt\% of PdO). Thus the substantial difference in the activity of two samples can be explained by the difference in their dispersion; the highly active sample $0.7 \mathrm{Pd} /$ $\mathrm{CeO}_{2}$ of lower $\mathrm{PdO}$ loading has smaller grains of $\mathrm{PdO}$ than the $1.6 \mathrm{Pd} / \mathrm{CeO}_{2}$, sample as can be inferred from a comparison of Fig. 2c, f. High dispersion of $0.7 \mathrm{Pd} / \mathrm{CeO}_{2}$ sample is connected with a higher number of active sites which is reflected by the higher absorbance of the methoxy bands formed after methane absorption (Fig. 6a). The difference in absorbance (absorbance ratio of the corresponding methoxy bands between $0.7 \mathrm{Pd} / \mathrm{CeO}_{2}$ and $1.6 \mathrm{Pd} / \mathrm{CeO}_{2}$ is 6 ) is proportional to the difference in the number of active sites (Lambert-Beer's law). This accounts for the observed difference in activity between two samples (see Fig. 1), where the ratio of the conversion of the two samples amounts also to 6. The reflections from $\mathrm{PdO}$ in the XRD patterns (Fig. 2b, c) are too small for any conclusions concerning the crystallinity of the samples simply because of low amount of the PdO on the support sample, but also due to its high dispersion. Let us note that the sample of higher dispersion and activity was obtained from a less concentrated solution (see section "Sample preparation").

In situ FTIR, utilising methanol as a universal probe molecule, allows thorough characterisation of different types of active centres on the catalyst surface as methanol, depending on the centre type, can be transformed into different products [53]. Thus, acidic sites give rise to methanol condensation into ether, while basic sites lead to the formation of carbonates. The redox sites convert methanol into formats which, in the consecutive reaction, can be oxidised further to mono or bidentates. For both samples, ceria supported and palladium-ceria supported catalysts, the formation of ether and formate products of methanol evolution on the surface at different temperatures evidences the presence of acidic and redox centres, respectively [53]. In addition, the palladium-ceria catalyst shows the presence of the basic sites as can be inferred from the appearance of carbonates. The centres typical of ceria are also present on the catalyst surface, which indicates that only part of the ceria surface is covered by $\mathrm{PdO}$ crystallites.

As regards the overall catalytic reaction mechanism, in situ FTIR analysis proves the Mars-van Krevelen mechanism for methane oxidation on palladium-ceria catalysts, as the formic or carbonate product groups appear under nonoxidative conditions during methane interaction with the catalyst surface. Indeed, the Mars-van Krevelen mechanism has already been considered in the literature [64-66]. In fact, there are several reaction pathways through which it can proceed. In a paper by Hurtado et al. [65], five models were discussed. One of them assumes the reaction of methane molecules with two catalyst active sites, which could be the case in regard to the palladium-ceria catalyst used in this study. It is very probable not only due to the weak palladium-oxygen bond which, enables easy oxidation of the reactants but also due to the oxidative properties of ceria, which can release oxygen under oxygen-lean conditions [31, 35-37].

It has also been a subject of debate whether catalytic combustion proceeds via the Eley-Rideal or Langmuir-Hinshelwood mechanisms [2, 67]. According to our study, methane was shown not to adsorb directly on the catalyst surface, but only in the oxygen preadsorbed surface which proves that the Langmuir-Hinshelwood mechanism can be excluded [62]. It should also be noted, that precise distinctions distinction between the Mars-van Krevelen and Eley-Rideal mechanisms is hard to achieve. For example, it is difficult to distinguish adsorbed oxygen and surface palladium oxide are in fact the same ensembles. Thus the reaction pathway assuming either adsorption of gaseous oxygen on the reduced palladium followed by methane reactive adsorption or methane reactive adsorption on the surface palladium oxide are in fact analogical and lead to the same products [64].

As pointed out in the introduction, the mechanism of methane combustion is still far from being fully understood. It is discussed in our previous work [62]. In that paper, different reaction intermediates are considered on the basis of in situ FTIR studies. In fact the literature is based on a few examples that deal with the problem. They included formate groups described in [55-58], monodentate, bidentate, as well as bridged carbonates and bicarbonates, carboxylates and free carbonates found in [55, 56, 59]. A simplified but valuable picture of possible reaction pathways can be provided by the study of $\mathrm{CO}$ adsorption. Different carbonates in the form of mono and bidentate, as well as bridged or free carbonates, were found on different catalysts. The band assignment of the specific forms of carbonates arising from $\mathrm{CO}$ adsorption can be found in [56, 68-72]. In our study, the monodentate form was found on the palladium-ceria catalyst upon $\mathrm{CO}$ adsorption, as evidenced by the appearance of the 1550,1330 and $1075 \mathrm{~cm}^{-1}$ bands (Fig. 7a, b). This is consistent with further findings of the intermediates during methane combustion (Fig. 8a, b), where monodentate formation was confirmed by the appearance of the bands at 1542 , 1340 and $1031 \mathrm{~cm}^{-1}(\nu \mathrm{C}-\mathrm{O})$. In fact, monodentates were the only stable intermediate to be detected on the catalyst surface. It seems that residual formate groups also detected in FTIR spectra are quickly converted to monodentate carbonates, which then form carbon dioxide through consecutive reaction.

It seems rather obvious that methane combustion proceeds on redox active centres, the presence of which was described by the results of adsorption of methanol on both ceria and palladium-ceria samples (Figs. 4, 5). Since the 
surface of the palladium-ceria catalyst is not fully covered by $\mathrm{PdO}$, as can be deduced from EDX mapping results (Fig. 2 $\mathrm{d}-\mathrm{h}$ ), redox centres from both oxides can be involved in the reaction, which was not discerned in this study. In addition, according to the mechanism proposed by Choudhary et al. [34], both acidic and basic surface active sites can play roles in methane activation but their exact role is unknown. Both types of active centres were recorded on palladium-ceria catalysts through methanol adsorption experiments (Fig. 5). However, due to the relatively simple picture of stable surface intermediates during methane combustion (monodentates detected in Fig. 8), their influence on the reaction progress cannot be easily justified.

\section{Conclusions}

The study is most of all an approach to the description of active centres and reaction intermediates in methane combustion on palladium-ceria supported catalysts of different palladium loadings. However, certain conclusions can also been made concerning the structure activity relationships for the two samples substantially differing in activity.

1. A significant difference in activity was noted for the palladium-ceria supported catalysts of two different loadings: $0.7 \mathrm{wt} \%$ and $1.6 \mathrm{wt} \%$. The maximum conversion $90 \%$ achieved for less loaded sample at $500{ }^{\circ} \mathrm{C}$ was 6 times higher than for more loaded one. The activity increase was correlated with increased $\mathrm{PdO}$ dispersion, which was qualitatively assessed by SEM results (Fig. 2) and also increased number of active sites determined from the methane sorption experiments (Fig. 6).

2. The active centres of ceria reference and palladium ceria supported catalysts were determined by in situ FTIR temperature programmed experiments using methanol as a probe molecule. There, different products of methanol evolution were assigned to the specific active centres. Two types of active centres were found for the ceria support acidic and redox centres, The palladium addition to ceria gave rise to the appearance of new acidic and redox centres as well as basic ones.

3. The methane sorption experiments without and with a presence of oxygen showed that methane oxidation on palladium ceria supported catalyst proceeds through formation of methoxy groups on the catalyst surface. This also indicates that one of the occurring mechanisms of methane oxidation is Mars-van Krevelen mechanism as the methane oxidation can proceed without a gaseous oxygen.

4. The stable surface intermediates that are formed on the palladium ceria supported catalyst are monodentate carbonates that were evidenced by both the in situ FTIR studies of $\mathrm{CH}_{4}$ sorption and methane oxidation. Their formation was confirmed by the in situ FTIR experiments using $\mathrm{CO}$ probe molecule.

Acknowledgements Financial support for this work was provided by Polish National Science Centre within Project Nos. 2016/23/B/ ST8/02024, 2017/25/N/ST8/01029 and also partly by 2013/09/B/ ST8/00171.

Open Access This article is distributed under the terms of the Creative Commons Attribution 4.0 International License (http://creativeco mmons.org/licenses/by/4.0/), which permits unrestricted use, distribution, and reproduction in any medium, provided you give appropriate credit to the original author(s) and the source, provide a link to the Creative Commons license, and indicate if changes were made.

\section{References}

1. Cullis CF, Willan BM (1983) J Catal 83:267

2. Baldwin TR, Burch R (1990) Appl Catal 66:337

3. Hicks RF, Qi H, Young ML, Le RG (1990) J Catal 122:280

4. Oh SH, Mitchell PJ, Siewert RM (1991) J Catal 132:287

5. Ribeiro FH, Chow M, Della Betta RA (1994) J Catal 146:537

6. Burch R, Urbano FJ (1995) Appl Catal A 124:121

7. Lee JH, Trimm DL, Fuel Proc. Technol. 42 (1995) 339

8. Schmitz PJ, Otto K, Devries JE (1992) Appl Catal A 92:59

9. Simmons GW, Wang Y-N, Marcos J, Klier K (1991) J Phys Chem 95:4522

10. Klier K, Hess JS, Herman RG (1997) J Chem Phys 107:4033

11. Hoflund GB, Li Z-H, Epling WS, Go"bel T, Schneider P, Hahn HW (2000) React Kinet Catal Lett 70:97

12. Li Z-H, Hoflund GB (1999) React Kinet Catal Lett 66:367

13. Choudhary TV, Banerjee S, Choudhary VR (2002) Appl Catal A 234:1

14. Gelin P, Primet M (2002) Appl Catal B 39:1

15. Zong Y, Li S, Niu F, Yao Q (2015) Proc Comb Inst 35: 2249

16. Lee JH, Trimm DL (1995) Fuel Process Technol 42:339

17. Epling WS, Hoflund GB (1999) J Catal 182:5

18. Hahn HW, Hesemann H, Epling WS, Hoflund GB, in: N.M. Rodriguez, S.L. Soled, J. Hubek (Eds.), In: Proceeding Fall 1997 MRS Meet.: Recent Adv. Catal. Mat., 497 (1998) 35

19. Baldwin TR, Burch R (1990) Catal Lett 6:131

20. Cullis CF, Willatt BM (1983) J Catal 83:267

21. Li Z-H, Hoflund GB (1999) React Kinet Catal Lett 66(2):367

22. Baldwin TR, Burch R (1990) Appl Catal 66:359

23. Hicks RF, Qi HH, Young ML (1990) J Catal 122:295

24. Hoflund GB, Li Z (2006) App Surf Sci 253:2830

25. Epling WS, Hoflund GB (1999) J Catal 182(1):5

26. Craciun R, Shereck B, Gorte RJ (1998) Catal Let 51:149-153 149

27. Thevenin PO, Alcalde A, Pettersson LJ, Jaras SG, Fierro JLG (2003) J Cat 215:78

28. Schwartz WR, Ciuparu D, Pfefferle LD (2012) J Phys Chem C 116:8587

29. Ciuparu D, Lyubovsky MR, Altman E, Pfefferle LD, Datye A (2002) Catal Rev 44:593

30. Kim G (1982) Ind Eng Chem Prod Res Dev 21:267

31. Trovarelli C (1996) Rev-Sci Eng 38:439

32. Trovarelli C, de Leitemburg M, Boaro G, Dolcetti (1999) Catal Today 50:353

33. Haneda M, Mizushima T, Kakuta N (1998) J Phys Chem 102:6579

34. Choudhary VR, Rane VH (1991) J Catal 130:411 
35. Summers JC, Ausen SA (1979) J Catal 58:131

36. Bhattacharyya A, Woltermann GM, Yoo JS, Karch JA, Cormier WE (1988) Znd Eng Chem Res 27:1356

37. Liu W, Flytzani-Stephanopoulos M (1995) J Catal 153:304

38. Gabriele Centi (2001) J Mol Catal A: Chem 173:287

39. Centi G (2001) J Mol Catal A: Chem 173:287

40. Martin D, Duprez D, Els Sci Pub, (1993) 201

41. Tuller HL, Nowich AS (1979) J Electrochem Soc 126:209

42. Tuller HL, Nowich AS (1975) J Electrochem Soc 122:255

43. Demoulin O, Navez M, Ruiz P (2005) Ap Catal A: Gen 295:59

44. Kung MC, Lin SS-Y, Kung HH (2012) Top Catal 55:108

45. Schmal M, Souza M, Alegre V, Dasilva M, Cesar D, Perez C (2006) Catal Tod 118:392

46. Zhang S, Shan J, Nie L, Nguyen L, Wud Z, F (Feng (2016) Tao Surf Sci 648:156

47. Murrel LL, Tauster SJ, Anderson DR (1991) Stud Surf Sci Catal $71: 275$

48. Farrauto RJ, Hobson MC, Kennelly T, Waterman EM (1992) Ap Catal A: Gen 81:227

49. Kennelly T, Farrauto RJ (1993) US patent 5216875:8

50. Lustemberg PG, Bosco MV, Bonivardi A, Busnengo HF, Ganduglia-Pirovano MV (2015) J Phys Chem C https://doi.org/10.1021/ acs.jpcc. 5 b05070

51. Burcham LJ, Briand LE, Wachs IE, Langmuir, 17 (2001) 6175

52. Busca G (1996) Catal Tod 27:457

53. Badlani M, Wach IE (2001) Catal Let $75: 3$

54. Socrates $\mathrm{G}$, Infrared and raman characteristic group frequencies, Third Edition (2001) ISBN 0470093072

55. Driscoll DJ, Martir W, Wang J, Lunsford JH (1985) J Am Chem Soc 107:58

56. Turek M, Wachs IE, DeCanio E (1992) J Phys Chem 96:5000

57. Lin-Vien D, Colthup N, Fateley W, Grasselli J (1991) The handbook of infrared and raman characteristic frequencies of organic molecules. Academic Press, San Diego
58. Becker E, Carlsson P-A, Skoglundh M, Top. Catal. 52 (2009) 1957

59. Lavalley JC (1996) Catal Today 27:377

60. Hadjiivanov KI, Vayssilov GN (2002) Catal 47:307

61. Choudhary TV, Banerjee S, Choudhary VR (2002) Rev Ap Catal A General 234:1

62. Jodłowski PJ, Jędrzejczyk RJ, Chlebda D, Gierada M, Łojewska J (2017) J Catal 350:1

63. Jodłowski PJ, Jędrzejczyk RJ, Rogulska A, Wach A, Kutrowski P, Sitarz M, Łojewski T, Kołodziej A, Łojewska J (2014) Spectrochim Acta A Mol Biomol Spectrosc 131:696

64. Garbowski E, Feumi-Jantou C, Mouaddib N, Primet M (1994) Appl Catal A Gen 109:277

65. Hurtado P, Ordóñez S, Sastre H, Díez FV (2004) Appl Catal B Environ 51:229

66. Stefanov P, Todorova S, Naydenov A, Tzaneva B, Kolev H, Atanasova G, Stoyanova D, Karakirova Y, Aleksieva K (2015) Chem Eng J 266:329

67. Berg M, Sven J (1994) Chem Eng 114:227

68. Porto SPS, Krishnan RS (1967) J Chem Phys 47:1009

69. Kilo M, Schildt C, Wokaun A, Baiker A (1992) J Chem Soc 88:1453-1457

70. Cmjak Z, Orel B (1996) Sol Energy Mater Sol Cells 40:205

71. Vuurman MA, Stufkens DJ, Oskam A, Goutam O, Wachs IE (1996) J Chem Soc Faraday Trans 92:3259

72. Wachs (1995) Colloids Surf A 105:143

Publisher's Note Springer Nature remains neutral with regard to jurisdictional claims in published maps and institutional affiliations. 